\title{
How Interplay between Photo and Thermal Activation Dictates Halide lon Segregation in Mixed Halide Perovskites
}

\author{
Elmelund, Tor; Seger, Brian; Kuno, Masaru K.; Kamat, Prashant V.
}

Published in:

ACS Energy Letters

Link to article, DOI:

10.1021/acsenergylett.9b02265

Publication date:

2020

Document Version

Peer reviewed version

Link back to DTU Orbit

Citation (APA):

Elmelund, T., Seger, B., Kuno, M. K., \& Kamat, P. V. (2020). How Interplay between Photo and Thermal Activation Dictates Halide Ion Segregation in Mixed Halide Perovskites. ACS Energy Letters, 5, 56-63. https://doi.org/10.1021/acsenergylett.9b02265

\section{General rights}

Copyright and moral rights for the publications made accessible in the public portal are retained by the authors and/or other copyright owners and it is a condition of accessing publications that users recognise and abide by the legal requirements associated with these rights.

- Users may download and print one copy of any publication from the public portal for the purpose of private study or research.

- You may not further distribute the material or use it for any profit-making activity or commercial gain

- You may freely distribute the URL identifying the publication in the public portal 


\title{
How Interplay between Photo and Thermal Activation Dictates Halide Ion Segregation in Mixed Halide Perovskites
}

\author{
Tor Elmelund ${ }^{1,3}$, Brian Seger ${ }^{3}$, Masaru Kuno ${ }^{1}$ and Prashant V. Kamat ${ }^{1,2^{*}}$ \\ ${ }^{1}$ Radiation Laboratory and Department of Chemistry \& Biochemistry \\ ${ }^{2}$ Department of Chemical \& Biomolecular Engineering \\ University of Notre Dame, Notre Dame, Indiana 46556, USA \\ and \\ ${ }^{3}$ SurfCat, Department of Physics \\ Technical University of Denmark \\ 2800 Kgs. Lyngby, Denmark
}

*Address correspondence to pkamat@nd.edu 


\section{Abstract}

The halide ion mobility in mixed halide perovskite exhibits two opposite trends in response to photo and thermal activation. While halides prefer to remain as Br-rich and I-rich domains under steady state light irradiation of $\left.\mathrm{MAPbBr}_{1.5}\right|_{1.5}$ films, they prefer to remain in their stable mixed composition when kept in the dark. The activation energies as determined from the temperature-dependent rate constants are $E_{\mathrm{a} \text {,forward }}=28.9 \mathrm{~kJ} \mathrm{~mol}^{-1}$ for photoinduced segregation and $E_{\mathrm{a} \text {,reverse }}=53.5 \mathrm{~kJ} \mathrm{~mol}^{-1}$ for remixing of halides in dark respectively. The energy input from photoexcitation assists to overcome the dark (thermally activated) mixing to induce $\mathrm{Br}$-rich and I-rich domains. This segregated state is maintained as long as the mixed halide film is irradiated continuously with visible light. The excitation intensity threshold above which segregation occurs follows a linear temperature dependence, such that phase separation occurs above $l_{\text {exc }}=30 \mu \mathrm{W} / \mathrm{cm}^{2}$ white light at $23^{\circ} \mathrm{C}$. The threshold at $90{ }^{\circ} \mathrm{C}$ becomes higher with minimum intensity requirement of $100 \mu \mathrm{W} / \mathrm{cm}^{2}$ to induce segregation. The thermodynamic rationale behind this unusual halide mobility under photo and thermal excitation discussed here can aid in understanding the stability issues of perovskite solar cells.

TOC Graphics

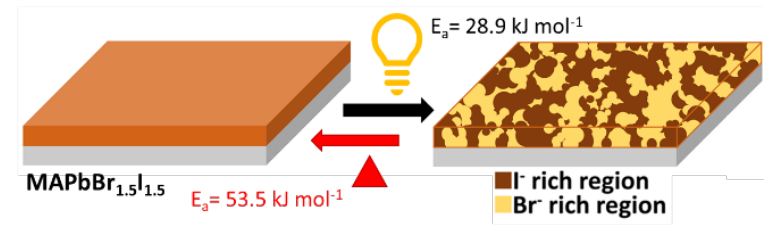


Significant strides have been made in recent years to boost the efficiency of metal halide perovskite solar cells. ${ }^{1-4}$ However, challenges remain to develop solar cells that can exhibit operational stability comparable to existing photovoltaic devices. In addition to intrinsic and surface defects, several other properties contribute to their operational instability. ${ }^{5}$ Efforts have been made to employ tri-cation (Cesium (Cs), methyl ammonium (MA) and formamidium (FA)) based perovskite films ${ }^{6,7}$ or surface treatments to improve the stability of perovskite solar cells. ${ }^{7-13}$

However, an intriguing aspect that influences the solar cell performance is the mobility of halide ions within the perovskite film. ${ }^{14-21}$ In fact, the crystalline liquid like property ${ }^{22}$ of these materials enables the movement of ions with relative ease. For example, we have recently shown that two different colloidal solutions or physically paired $\mathrm{MAPbBr}_{3}$ and $\mathrm{MAPbl}_{3}$ films, when combined, undergo quick exchange of halide ions driven through thermal activation. ${ }^{23-25}$ The difference in spectral features of bromide and iodide perovskite films enables tracking of the movement of halide ions. The rate of remixing (or homogenization) process increases with increasing temperature, thus suggesting thermally activated process dictating the mixing/exchange of halide ions. Techniques such as emission, impedance spectroscopy, transient capacitance and infrared imaging have proven useful to track the ion mobility in perovskite films. ${ }^{16,26-30}$

Whereas entropy of mixing explains the thermally activated mixing of halide ions to yield mixed halide perovskite, ${ }^{26,31,32}$ an opposite trend is observed when the mixed halide film is subjected to photoirradiation. This process commonly referred to as photoinduced phase segregation or halide segregation yields $\mathrm{Br}$-rich and I-rich perovskite domains..$^{33-35}$ As the mixed halide perovskite phase segregates, the I-rich domains act as recombination sites for the photogenerated charge carriers. The formation of these recombination sites has been shown to limit the performance of halide perovskitebased solar cells. ${ }^{15,36,37}$

The interesting aspect of halide segregation is its reversibility. We see a total recovery when the film is left in the dark as thermal activation drives the segregated domains back to the original homogenized composition. Several models have been proposed to explain photoinduced segregation of halides. These include; two state model in the excited state, polaron-induced lattice strain, defect-driven halide ion movement and overcoming the thermal activation of mixing with bandgap excitation. ${ }^{8,26,34,38-43}$

The two different types of halide ion movement, viz., the photoinduced phase segregation and the subsequent recovery process under dark conditions, are summarized through the expressions (reactions 1 and 2):

$$
\begin{aligned}
& \text { In light: } n \mathrm{MAPbBr}_{1.5} \mathrm{I}_{1.5} \stackrel{\mathrm{h} v}{\longrightarrow}(\mathrm{n} / 2) \mathrm{MAPbBr}_{3}+(n / 2) \mathrm{MAPb}_{3} \\
& \text { In dark: }(n / 2) \mathrm{MAPbBr}_{3}+(n / 2) \mathrm{MAPbl}_{3} \longrightarrow n \mathrm{MAPbBr}_{1.5} \mathrm{I}_{1.5}
\end{aligned}
$$

In other words, the stable geometry without irradiation (i.e. in the dark) is the mixed or homogeneous state while the halide ions prefer to remain segregated under continuous photoirradiation. Note that Reactions 1 and 2 are idealized expressions since the $\mathrm{Br}: \mathrm{I}$ ratio can vary to create Br-rich and I-rich domains. Since the entropically driven remixing and segregation processes compete under photoirradiation, it is important to establish how photoexcitation overcomes the entropy of mixing and 
the driving force behind such unusual activity. In order to obtain insight into these two processes we have now undertaken temperature-dependent studies of segregation and dark recovery kinetics. The kinetic and thermodynamic arguments that explain the photoinduced halide segregation and dark recovery are discussed.

Mixed halide films of $\mathrm{MAPbBr}_{1.5} \mathrm{I}_{1.5}$ were cast on $0.5 \mu \mathrm{m}$ FTO covered glass slides using static drop casting. A $0.9 \mathrm{M}$ solution of $0.45 \mathrm{M} \mathrm{Pbl}_{2}, 0.45 \mathrm{M} \mathrm{MAl}, 0.45 \mathrm{M} \mathrm{PbBr}_{2}$ and $0.45 \mathrm{M} \mathrm{MABr}$ was dissolved in $0.9 \mathrm{M}$ dimethyl sulfoxide (DMSO), such that a molar ratio of (1:1:1:1) was obtained, which was then mixed with dimethylformamide (DMF) to obtain the precursor solution. The spin coated films on glass slides were subsequently annealed at $65{ }^{\circ} \mathrm{C}$ on a hotplate for 1 minute followed by immediate annealing at $100{ }^{\circ} \mathrm{C}$ for 2 minutes to facilitate the nucleation process of adjacent grains. Through XPS analysis it was confirmed that the films had a 1:1 composition of $\mathrm{Br}$ and I (See Supporting Information Figure S1). A film thickness of $235 \mathrm{~nm}$ was determined through cross-sectional SEM (See Supporting Information Figure S2). To suppress the atmospheric degradation at elevated temperatures these films were covered with a blank glass slide and clamped with binder clips. The directly synthesized $\mathrm{MAPbBr}_{1.5} \mathrm{l}_{1.5}$ films were found to have somewhat of a segregated composition. To homogenize the films prior to any experiments, the films were left on a hotplate at $100{ }^{\circ} \mathrm{C}$ for 4 hours. The films were then placed in a spectrophotometer with a Peltier thermal setup and subjected to light/heat treatment. The steady state UV-VIS absorption spectra were recorded to track the photoactivated and thermally activated mobility of halide ions. All experiments where the photoactivated halide ion mobility was probed, a white light source was used to simulate operating conditions. A spectrum of the tungsten halogen lamp employed for photoirradiation can be found in the Supporting Information Figure $\mathbf{S 3 .}$

Photoactivated mobility of halide ions. When the mixed halide perovskite film is subjected to visible light irradiation, we observed a loss of the excitonic peak and increased absorbance in the red region (Figure 1A). The difference absorption spectra recorded in Figure 1B show these changes with an isosbestic point around $630 \mathrm{~nm}$. This further shows the photoinduced conversion of $\mathrm{MAPbBr}_{1.5} \mathrm{I}_{1.5}$ into $\mathrm{Br}$-rich and I-rich regions confirming the observations as reported in earlier studies. ${ }^{26,34,38,39,42}$ The presence of an isosbestic point between the depletion of mixed halide absorption and iodide rich domain absorption shows the existence of two different forms. With increasing irradiation time, the concentration of segregated forms increases.

The prominent bleach at $616 \mathrm{~nm}$ and the induced absorption at $642 \mathrm{~nm}$ was tracked to determine the rate of halide segregation (Reaction 1 ). To determine how the light intensity (lexc) changes the segregation rate, a study was carried out where the illumination intensity was varied (Figure 1C). Absorption spectra for the additional intensities can be found in Supporting Information Figure S4. All kinetic traces were fitted with monoexponential fittings to determine the rate constants.

Figure 1D shows that first order rate constants increase with increasing intensity of excitation. The rate constant increases from $k_{\text {forward }}=0.3 \times 10^{-3} \mathrm{~s}^{-1}$ at $l_{\mathrm{exc}}=20 \mathrm{~mW} / \mathrm{cm}^{2}$ to $k_{\text {forward }}=1.2 \times 10^{-3} \mathrm{~s}^{-1}$ when the intensity is increased to $l_{\text {exc }}=60 \mathrm{~mW} / \mathrm{cm}^{2}$. More relevantly, linear behavior of $\ln \left(k_{\text {forward }}\right)$ versus $l_{\text {exc }}$ immediately suggests an exponential dependence of the rate constant with photogenerated carrier density. We can express the forward rate constant for the halide segregation in the form of Equation $\mathbf{3}$, 


$$
k_{\text {forward }} \propto A e^{-\left[\frac{-\left|\Delta E_{\text {light }}\right|+E_{\text {a,reverse }}}{k T}\right]}
$$

where $A$ is a proportionality constant, $E_{a}$,reverse is the native activation energy for anion migration and $\Delta E_{\text {light }} \propto I_{\text {exc }} . \Delta E_{\text {light }}$ is ultimately related to carrier density dependent energetic differences in band gaps between iodide rich domains and the parent mixed halide. ${ }^{26,43}$ This energy input $\left(\Delta E_{\text {light }}\right)$ assists in overcoming the energy barrier of remixing $\left(E_{a, \text { reverse }}\right)$. At a given temperature $\ln \left(k_{\text {forward }}\right)$ should therefore exhibit a linear dependency with $l_{\text {exc }}$, as corroborated by the data in Figure 1D.

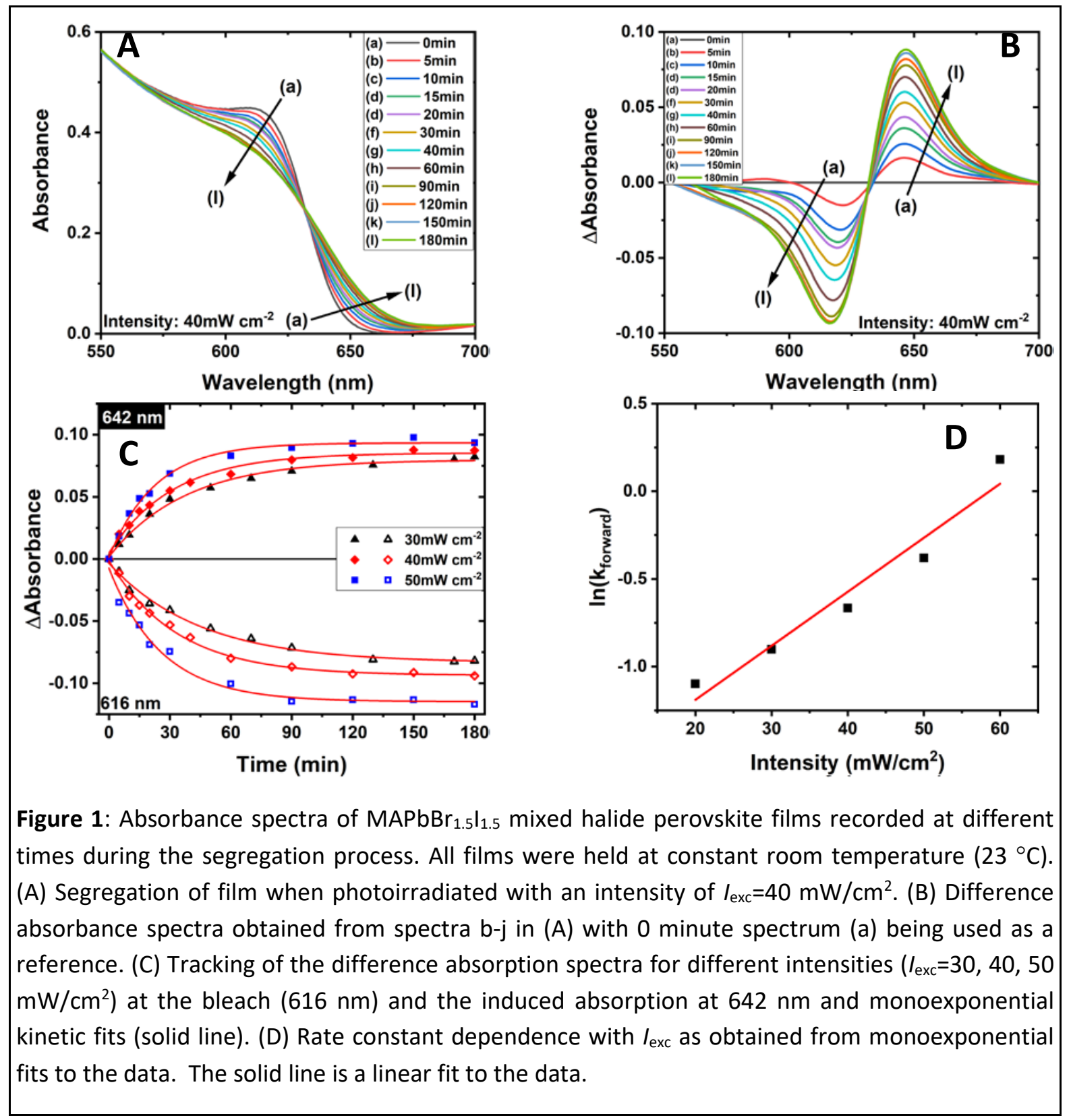


Many different models have been proposed to explain the halide ion mobility under light irradiation. The defects arising from halide ion vacancies seems to play a role in driving the halide ions away from each other. ${ }^{34,40,43-49}$ The trapping of holes by iodide also plays a role in inducing the halide ion mobility. ${ }^{50}$ As discussed in earlier studies, the intensity threshold observed for photosegregation shows the requirement to overcome the thermodynamic activation barrier for making halide ions move away from each other. ${ }^{26,43}$

Thermally activated remixing of halide ions. When previously photoirradiated mixed halide films (i.e. halide ion segregated films) were stored in the dark the original mixed halide form was restored thus confirming the mobility of halide ions in the opposite direction (Reaction 2). This bidirectional movement of halide ions was similar to our earlier study showing the exchange of $\mathrm{Br}$ and $\mathrm{I}$ in paired films of $\mathrm{MAPbBr}_{3}$ and $\mathrm{MAPbl}_{3}$ films with thermal activation. ${ }^{25}$ The aim was therefore to study the thermal effect on recovery, using films that had been fully segregated under the same conditions $\left(l_{\text {exc }}=30\right.$ $\mathrm{mW} / \mathrm{cm}^{2}$ at $23^{\circ} \mathrm{C}$ ). At room temperature, it took 14 hours for pre-segregated mixed halide ion film to recover fully, thus showing the slow mobility of halide ions. However, with increasing temperature one can significantly increase the rate of dark recovery (viz., mixing of halide ions to original mixed halide composition). For example, when the photosegregated halide film was kept in the dark at $80{ }^{\circ} \mathrm{C}$, it took just 20 minutes for the film to recover and attain the original mixed halide composition. Figures $\mathbf{2}$ (A-D)
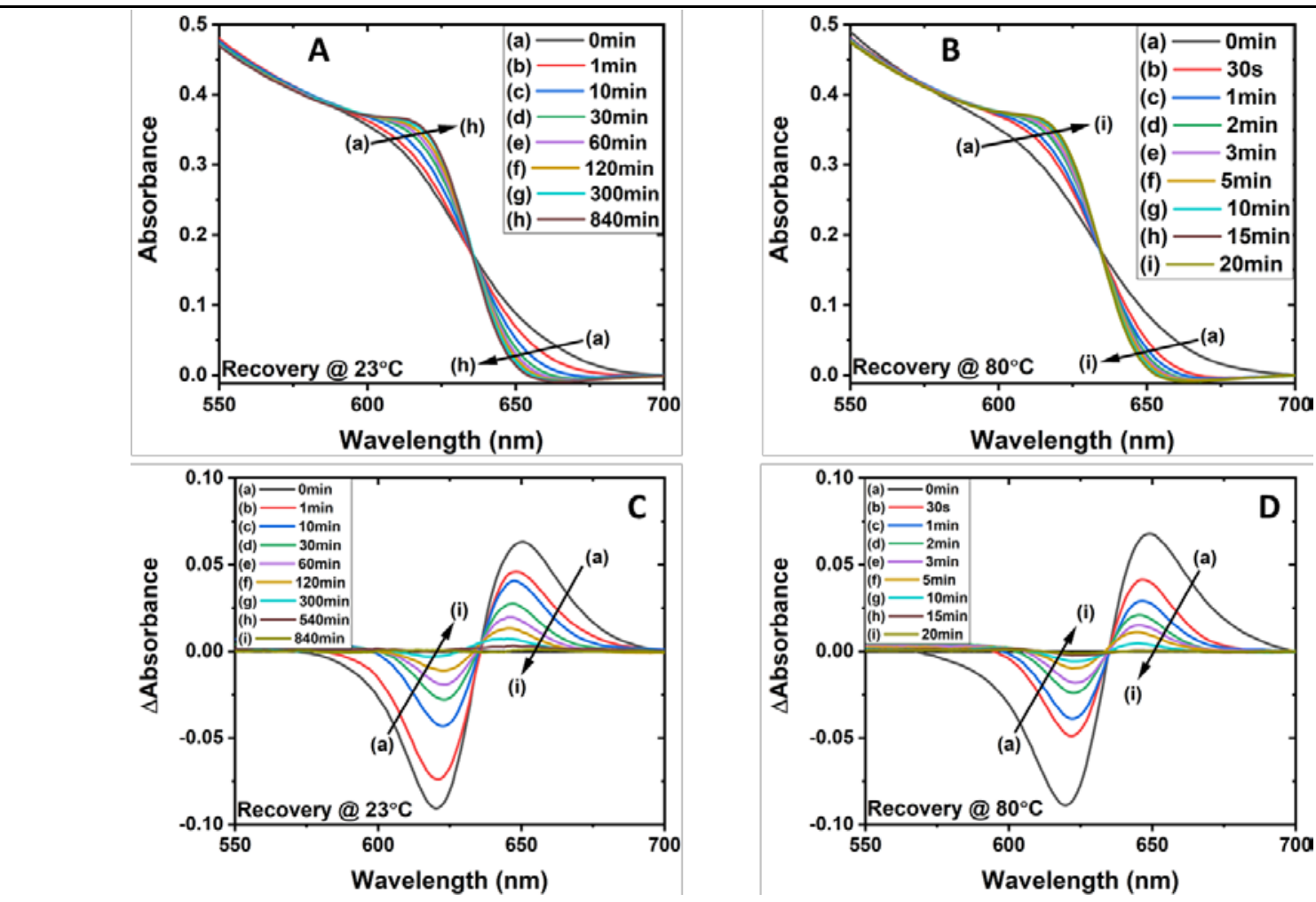

Figure 2: Absorbance spectra of $\mathrm{MAPbBr}_{1.5} \mathrm{I}_{1.5}$ mixed halide perovskite films recorded at different timepoints of the recovery process. (A, B) Recovery of pre-segregated films when recovered at room temperature $\left(23^{\circ} \mathrm{C}\right)$ and when subjected to $80^{\circ} \mathrm{C}$. (C, D) Difference absorbance spectra obtained from $(A, B)$ showing the reversible recovery process until their initial position is attained. The absorbance spectra of the original $\mathrm{MAPbBr}_{1.5} \mathrm{l}_{1.5}$ film (before subjecting it to photoirradiation) is used as reference. 
show dark recovery of the pre-photosegregated films at $23^{\circ} \mathrm{C}$ and $80^{\circ} \mathrm{C}$.

The difference spectra were recorded using the absorbance spectra of the original $\left.\mathrm{MAPbBr}_{1.5}\right|_{1.5}$ film (before subjecting it to photoirradiation) as reference. Thus, the spectra $a$ in Figures $\mathbf{2 C}$ and 2D correspond to the segregated halide ion state (i.e. immediately after stopping the photoirradiation). With increasing time, the recovery shows a trend that is opposite to the one observed during the photoirradiation. The presence of an isosbestic point (Figures 2C and 2D) at both these temperatures confirm that the recovery represents the existence of two states (viz: segregated and mixed halide composition) and the concentration of these domains are decreased with increasing time of dark recovery.

To study the thermal effect on the rate of dark recovery, difference absorbance spectra for all the recorded temperatures were monitored at the two peak positions. Figure $\mathbf{3 A}$ shows the tracked recovery of the absorption at $620 \mathrm{~nm}$ and induced absorption at $650 \mathrm{~nm}$ for $23^{\circ} \mathrm{C}, 70{ }^{\circ} \mathrm{C}$ and $80{ }^{\circ} \mathrm{C}$. It is evident that rate of recovery significantly increases as the temperature is increased. The time required for the films to fully recover is shown in Figure 3B. This temperature dependent dark recovery shows the importance of thermal activation in inducing the mobility of halide ions, thus reversing the trend observed during photoirradiation. All traces in Figure 3A together with the additional temperatures (See Supporting Information Figure S5), were fit to monoexponential decays to determine pseudo first order rate constants for the dark recovery. This dependence on temperature was further analyzed through the Arrhenius expression

$$
\ln \left(k_{\text {reverse }}\right)=-E_{a, \text { reverse }} / R T+\ln (A)
$$


where $A$ is a preexponential constant. The plot of $\ln \left(k_{\text {reverse }}\right)$ versus inverse temperature shown in Figure 3C exhibits a linear relationship. The activation energy corresponding to Reaction $\mathbf{2}$, as determined from
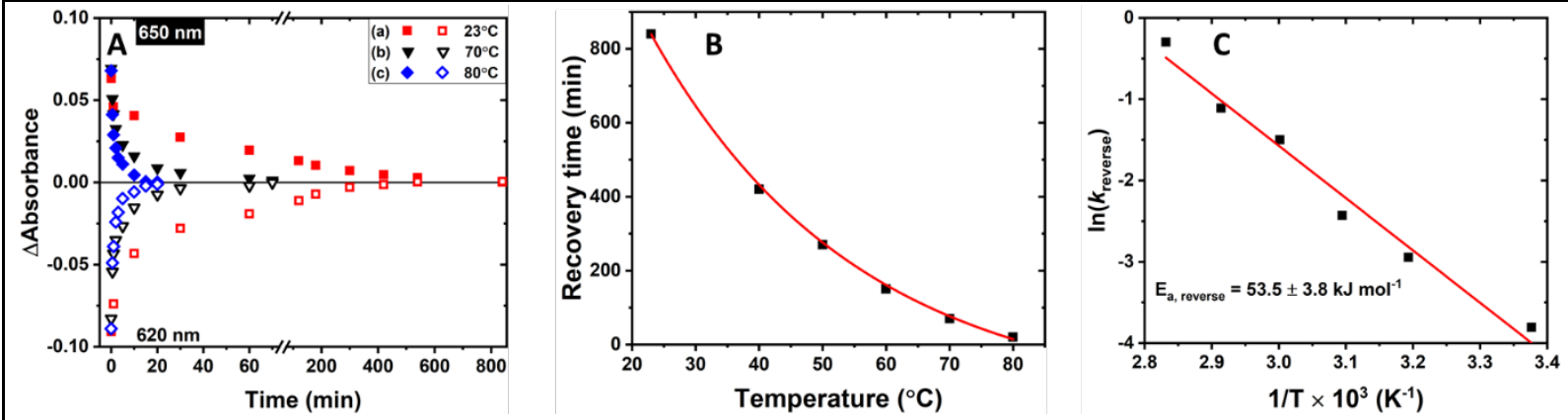

Figure 3: Change in absorbance for the initial fully segregated position of the $\left.\mathrm{MAPbBr}_{1.5}\right|_{1.5}$ mixed halide perovskite. (A) Tracking of the difference absorption spectra for different recovery temperatures (a) $23^{\circ} \mathrm{C}$ (Figure 2C), (b) $70^{\circ} \mathrm{C}$ and (c) $80^{\circ} \mathrm{C}$ (Figure 2D) at the bleach $(620 \mathrm{~nm}$ ) and the induced absorption at $650 \mathrm{~nm}$. (B) Extracted recovery times from (A) where data points are the averaged recovery time for the bleach and induced absorption, together with additional temperatures shown in Figure S5, showing a significant decrease in recovery time as temperature is increased. The solid line is a monoexponential fit to the data. (C) Arrhenius plot of natural log of the rate constants versus the inverse of temperature, where an average of the extracted rate constants for the recovery of the bleach and induced absorption is used, with the rate constants being extracted from monoexponential fits of (A). The solid line is a linear fit to extract activation energy, $E_{\text {a,reverse. }}$

the slope of the plot, is $E_{\mathrm{a}}$ reverse $=53.5 \pm 3.8 \mathrm{~kJ} \mathrm{~mol}^{-1}$. This value is similar to the activation energy $\left(E_{\mathrm{a}}=50.7\right.$ $\mathrm{kJ} \mathrm{mol}{ }^{-1}$ ) that was determined from the exchange of halide ions between physically paired of $\mathrm{MAPbBr}_{3}$ and $\mathrm{MAPbl}_{3}$ films, which we recently showed. ${ }^{25}$

These results show the thermodynamic activation barrier for observing mobility of halide ions in perovskite films. As discussed earlier, the entropy of mixing plays an important role in attaining the mixed halide composition with an energy of activation of $E_{a}$,reverse $=53.5 \mathrm{~kJ} \mathrm{~mol}^{-1}$. This estimate of activation energy differs from the value $28 \mathrm{~kJ} \mathrm{~mol}^{-1}(0.29 \mathrm{eV})$ obtained for iodide diffusion from the transient capacitance measurements. The activation energy obtained in the present study is a direct estimate observed through both $\mathrm{Br}$ - and I- ion diffusion and agrees well with the estimate of $59 \mathrm{~kJ} \mathrm{~mol}^{-1}$ (or $0.62 \mathrm{eV}$ ) observed with photocurrent measurements ${ }^{51}$ and $50.7 \mathrm{~kJ} \mathrm{~mol}^{-1}$ obtained with halide ion exchange between two pressed films. ${ }^{25}$

Halide ion mobility under combined photo and thermal activation. The experiments described above highlight the two competing reactions presented in Reaction $\mathbf{1}$ and $\mathbf{2}$ for photoactivated and thermally activated halide ion mobility. Under photoexcitation the bromide and iodide prefer to remain separate as iodide rich and bromide rich domains, while in dark they prefer to stay together with homogenized or mixed halide composition. The obvious question is how combined photo and thermal effects influence the entropically-driven remixing. Again, mixed halide $\mathrm{MAPbBr}_{1.5} \mathrm{I}_{1.5}$ films were prepared as described in 
the Supporting Information, and then subjected to photoirradiation (constant intensity of $l_{\text {exc }}=20$ $\mathrm{mW} / \mathrm{cm}^{2}$ ) at different temperatures. The results are shown in Figure 4.

Figure 4A shows the difference absorption spectra recorded during photoirradiation of $\mathrm{MAPbBr}_{1.5} \mathrm{I}_{1.5}$ at $100{ }^{\circ} \mathrm{C}$. Similar experiments were carried out at different temperatures (See Supporting Information Figure S6), and the absorbance change monitored at 620 and $650 \mathrm{~nm}$ were recorded. Figure 4B shows kinetic traces of halide ion segregation observed at $23{ }^{\circ} \mathrm{C}, 60{ }^{\circ} \mathrm{C}$, and $100{ }^{\circ} \mathrm{C}$. Here it is evident that $k_{\text {forward }}$ increases with increasing temperature in agreement with Equation 3.
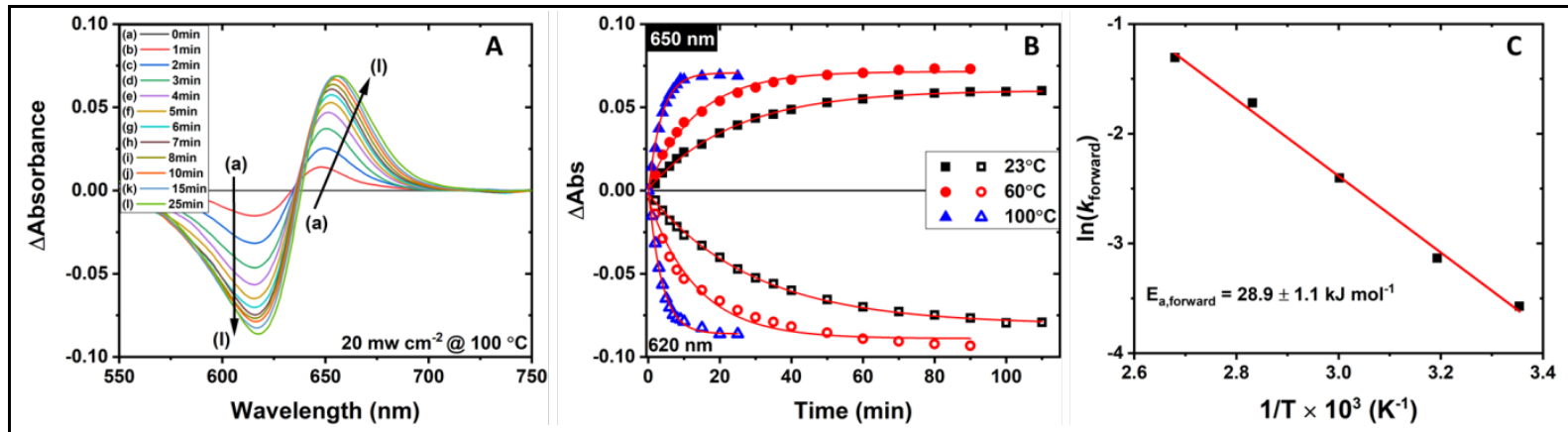

Figure 4: Absorbance spectra of $\left.\mathrm{MAPbBr}_{1.5}\right|_{1.5}$ mixed halide perovskite under constant photoirradiation $\left(l_{\mathrm{exc}}=20 \mathrm{mw} / \mathrm{cm}^{2}\right)$ when held at elevated temperatures. (A) Difference absorbance spectra acquired at interval timepoints when held at $100{ }^{\circ} \mathrm{C}$. (B) Tracking of the segregation evolution for different annealing temperatures $\left(23^{\circ} \mathrm{C}, 60^{\circ} \mathrm{C}\right.$, and $\left.100^{\circ} \mathrm{C}\right)$ at the bleach $(620 \mathrm{~nm})$ and the induced absorption at $650 \mathrm{~nm}$. Traces shown in solid lines are monoexponential decay kinetics fits. (C) Arrhenius plot of natural log of the rate constants versus the inverse of temperature, with the average rate constants for the bleach and induced absorption extracted from monoexponential fits of (B).

This $k_{\text {forward }}$ dependence on temperature is attributed to the light energy that mobilizes the halide ions, which then have a lower activation barrier causing I-rich and $\mathrm{Br}$-rich domains to form faster. All traces $\left(23^{\circ} \mathrm{C}, 60^{\circ} \mathrm{C}\right.$, and $\left.100{ }^{\circ} \mathrm{C}\right)$ in Figure $4 \mathrm{~B}$, together with $40^{\circ} \mathrm{C}$ and $80^{\circ} \mathrm{C}$ shown in the Supporting Information, were fitted to monoexponential decay to determine the rate constants $\left(k_{\text {forward }}\right)$. Using these average rate constants for the bleach and induced absorption, the Arrhenius plot of $\ln \left(k_{\mathrm{forward}}\right)$ versus inverse temperature in Figure $\mathbf{4 C}$ shows a linear relationship. The effective activation energy determined from the slope of this linear fit is $E_{\mathrm{a} \text {,forward }}=28.9 \pm 1.1 \mathrm{~kJ} \mathrm{~mol}^{-1}$, which is lower than that determined for the homogenization of mixed halide perovskite films ( $E_{a}$,reverse). This lower activation energy of photosegregation overcomes the larger activation barrier of thermal mixing and thus favors halide ion segregation. Further work is therefore required to develop effective ways of increasing the activation energy related to photosegregation at high intensities. Attempts have been made to retard the phase segregation by improving crystallinity and grain size, while surface treatments using an electron-donating ligand such as trioctylphosphine oxide have been reported to significantly reduce the onset of the halide segregation in mixed halide perovskite. ${ }^{8,17,34,43}$

\section{Excitation intensity threshold for light-induced halide segregation}


As discussed above, light-induced halide segregation is not suppressed even at temperatures up to $100{ }^{\circ} \mathrm{C}$ for $l_{\text {exc }}$ values above $l_{\text {exc }}=20 \mathrm{~mW} / \mathrm{cm}^{2}$. It was therefore necessary to significantly lower the excitation intensity to establish an equilibrium between Reactions $\mathbf{1}$ and $\mathbf{2}$. Here, prior studies of lightinduced halide phase segregation have suggested an excitation intensity threshold ( $l_{\text {exc,threshold }}$ ) of order $l_{\text {exc,threshold }} \sim 100 \mu \mathrm{W} / \mathrm{cm}^{2}$ for light-induced halide segregation. ${ }^{26,43}$ Figure 5 shows recorded absorption spectra of $\left.\mathrm{MAPbBr}_{1.5}\right|_{1.5}$ films subjected to (broadband white light) $l_{\text {exc }}$-values of $30 \mu \mathrm{W} / \mathrm{cm}^{2}$ and 100 $\mu \mathrm{W} / \mathrm{cm}^{2}$ at $23{ }^{\circ} \mathrm{C}$ and $90{ }^{\circ} \mathrm{C}$ respectively (Figure 5A: $l_{\mathrm{exc}}=30 \mu \mathrm{W} / \mathrm{cm}^{2}$ and $23{ }^{\circ} \mathrm{C}$; Figure 5B: $l_{\mathrm{exc}}=100$ $\mu \mathrm{W} / \mathrm{cm}^{2}$ and $90{ }^{\circ} \mathrm{C}$ ). Absorption spectra were recorded over 10 hours of continuous illumination to establish whether any segregation occurred at these low intensities. In both cases, the data show virtually no change of $\mathrm{MAPbBr}_{1.5} \mathrm{I}_{1.5}$ absorption spectra, suggesting the suppression of halide phase segregation. Figures 5C and 5D show difference absorption spectra for the two cases, corroborating the claim.

Increasing $l_{\text {exc }}$ above $30 \mu \mathrm{W} / \mathrm{cm}^{2}$ at $23^{\circ} \mathrm{C}$, however, leads to slow phase segregation. Data acquired at $l_{\text {exc }}=40 \mu \mathrm{W} / \mathrm{cm}^{2}$ and $80 \mu \mathrm{W} / \mathrm{cm}^{2}$ are shown in Figure S7. An excitation intensity threshold of $l_{\text {exc,threshold }} \approx 30 \mu \mathrm{W} / \mathrm{cm}^{2}$ is therefore established at $23^{\circ} \mathrm{C}$ with a time of exposure of 10 hours.

Identical experiments conducted at $90{ }^{\circ} \mathrm{C}$ reveal an elevated intensity threshold value of $I$ exc,threshold $\approx 100 \mu \mathrm{W} / \mathrm{cm}^{2}$. In fact, by conducting experiments at different temperatures between $23^{\circ} \mathrm{C}$ and

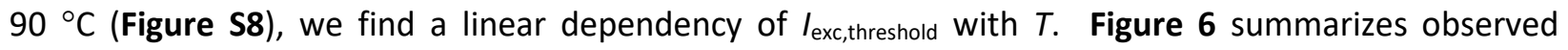

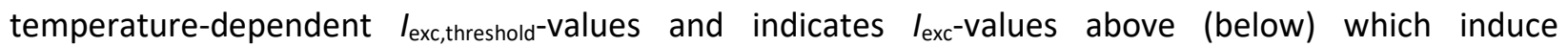
(suppress) light-induced halide segregation at a given temperature. This is analogous and complementary to a photostability phase diagram linking $l_{\text {exc }}$ and carrier diffusion lengths previously found for $\mathrm{MAPb}\left(\mathrm{Br}_{\mathrm{x}} \mathrm{I}_{\mathrm{x}}\right)_{3}$ thin films. ${ }^{26}$

The results in Figure 6 are important to developing a microscopic understanding of light-induced halide phase segregation. Namely, existence of an excitation intensity threshold for phase segregation argues against a polaron strain model. ${ }^{32}$ Such phenomenon has no intensity threshold for observing segregation. Moreover, the linear temperature dependency of $l_{\text {exc,threshold }}$ qualitatively agrees with the microscopic model developed earlier. ${ }^{43}$ The underlying concept is that the additional energy from photogenerated carriers in the perovskite film influence ion migration dynamics. By balancing phase segregation and dark recovery probabilities, one finds the following expression (Equation 5) for excitation intensity threshold to observe halide segregation, 

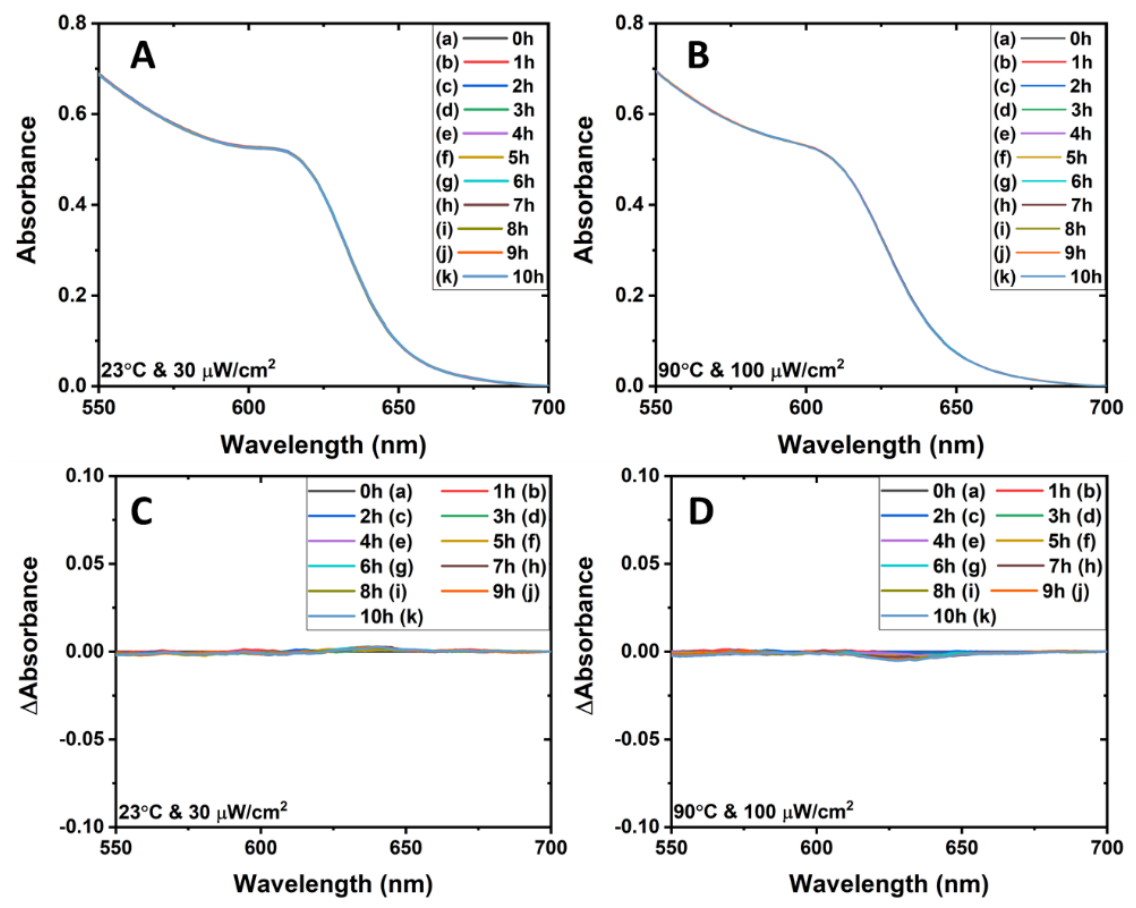

Figure 5: Absorbance spectra of $\mathrm{MAPbBr}_{1.5} \mathrm{I}_{1.5}$ mixed halide perovskite films held at different temperature and intensity pairs over the course of ten hours, (A) $23{ }^{\circ} \mathrm{C}$ and $l_{\text {exc }}=30 \mu \mathrm{W} / \mathrm{cm}^{2}$, and (B) $90{ }^{\circ} \mathrm{C}$ and $l_{\text {exc }}=100 \mu \mathrm{W} / \mathrm{cm}^{2}$. (C,D) Corresponding difference absorbance spectra obtained from $(A, B)$ where the 0 minute spectrum has been subtracted from all spectra recorded at different times.

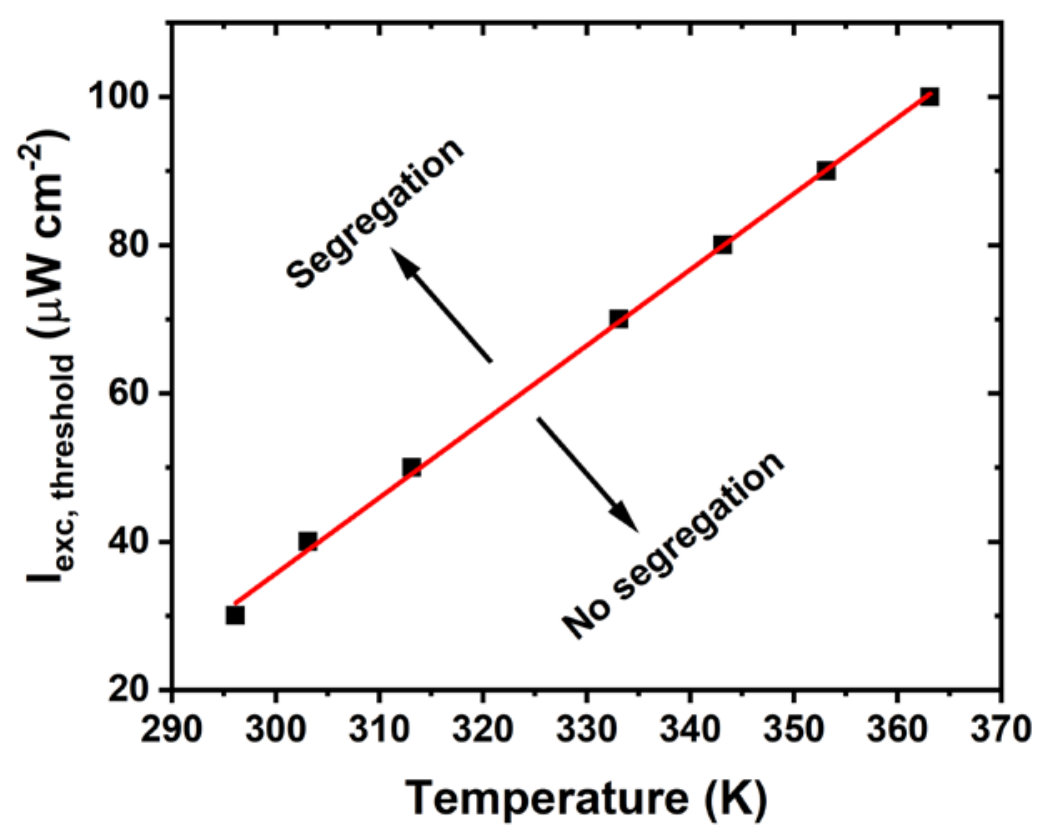

Figure 6: $l_{\text {exc,threshold }}$ as a function of temperature for observing halide ion segregation in $\left.\mathrm{MAPbBr}_{1.5}\right|_{1.5}$ mixed halide perovskite films. Below the recorded $l_{\text {exc,threshold }}$ for each temperature, no halide ion segregation of the films could be observed. 


$$
I_{\text {exc,threshold }}=\left(\frac{k T^{*}}{\Delta E_{\mathrm{g}, \text { domain }}}\right)\left(\frac{h v}{\alpha}\right)\left(\frac{1}{\tau V_{\mathrm{e} / \mathrm{h}}}\right)
$$

where $\Delta E_{\mathrm{g}, \text { domain }}$ is an energy associated with exchanging $\mathrm{Br}^{-}$with $\mathrm{I}^{-}$within phase segregated domains, $h v$ is the excitation energy, $\alpha$ is the perovskite absorption coefficient, $\tau$ is the carrier lifetime, and $V_{\mathrm{e} / \mathrm{h}}$ is a geometrical volume linked to carrier diffusion lengths. $T^{*}$ is an effective temperature, which differs from the absolute system temperature $T$, through inclusion of attractive/repulsive interactions between $\mathrm{I}^{-}$and $\mathrm{Br}^{-}$underlying $\mathrm{MAPb}\left(\mathrm{I}_{1-\mathrm{x}} \mathrm{Br}_{\mathrm{x}}\right)^{\prime}$ 's mixing enthalpy. Most relevant about Equation $\mathbf{5}$ is that it predicts a

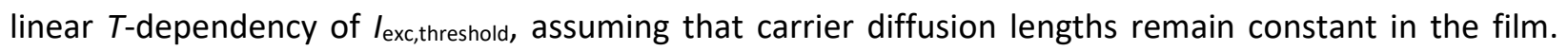
Furthermore, using nominal values of $\Delta E_{\mathrm{g} \text {,domain }} \approx 3.6 \mathrm{meV} /$ atom, ${ }^{43} \mathrm{hv}=3 \mathrm{eV}, \mathrm{kT}=25 \mathrm{meV}, \alpha=10^{5} \mathrm{~cm}^{-1}$, $\tau=100 \mathrm{~ns}^{26}$ and $V_{\mathrm{e} / \mathrm{h}}=4.2 \times 10^{-12} \mathrm{~cm}^{3}$ (associated carrier diffusion length of $l_{\mathrm{e} / \mathrm{h}} \approx 1 \mu \mathrm{m}$ ) we find a room temperature intensity threshold of $80 \mu \mathrm{W} / \mathrm{cm}^{2}$. This value is in good agreement with the experimental values found here as well with previous emission measurements using diode laser excitation ${ }^{26,43}$

To summarize, three separate sets of experiments were conducted to elucidate the kinetics and thermodynamic driving force responsible for photoinduced segregation in $\mathrm{MAPbBr}_{1.5} \mathrm{I}_{1.5}$ mixed halide perovskite films. First, the photoactivated halide ion mobility was probed by illuminating the samples with different intensities at $23{ }^{\circ} \mathrm{C}$. This was done to determine $k_{\text {forward }}$ values, which were found to increase from $k_{\text {forward }}=0.3 \times 10^{-3} \mathrm{~s}^{-1}$ at $l_{\mathrm{exc}}=20 \mathrm{~mW} / \mathrm{cm}^{2}$ to $k_{\text {forward }}=1.2 \times 10^{-3} \mathrm{~s}^{-1}$ at $l_{\mathrm{exc}}=60 \mathrm{~mW} / \mathrm{cm}^{2}$. Second, $k_{\text {reverse }}$ was probed by subjecting pre-segregated films to elevated temperatures to increase the rate of dark recovery. It was found, that as the annealing temperature increased, the rate of halide diffusion increased following an Arrhenius relationship with an activation energy of $E_{\text {a,reverse }}=53 \mathrm{~kJ} \mathrm{~mol}^{-1}$. Third, $\left.\mathrm{MAPbBr}{ }_{1.5}\right|_{1.5}$ films were subjected to both photoexcitation and heat treatment to determine the rate of segregation. Here the illumination intensity of $l_{\text {exc }}=20 \mathrm{~mW} / \mathrm{cm}^{2}$ was held constant while the temperature was varied. This study found that as the temperature was increased, $k_{\text {forward }}$ increased following an Arrhenius relationship with an effective activation energy of $E_{\mathrm{a} \text {, forward }}=29 \mathrm{~kJ} \mathrm{~mol}^{-1}$. This lower activation energy of the photoactivated segregation enables perovskite films to overcome the entropically driven mixing and create $\mathrm{Br}$-rich and I-rich domains. The halide segregation prevails as long as the mixed halide film is irradiated continuously with visible light. When the intensity was lowered to establish equilibrium between the two competing reactions, our study found that the intensity had to be significantly decreased. Excitation intensity thresholds of $l_{\text {exc,threshold }}=30 \mu \mathrm{W} / \mathrm{cm}^{2}$ and $l_{\text {exc, threshold }}=100 \mu \mathrm{W} / \mathrm{cm}^{2}$ were established for $T=23{ }^{\circ} \mathrm{C}$ and $T=90{ }^{\circ} \mathrm{C}$ respectively. Moreover, $l_{\text {exc, threshold was found to follow a linear }}$ temperature dependence in qualitative agreement with a microscopic model for phase segregation, thus confirming the interplay between thermally driven mixing and photodriven segregation of bromide and iodide ions.

The results presented here provide an insight into photo and thermal activation of halide ion mobility in

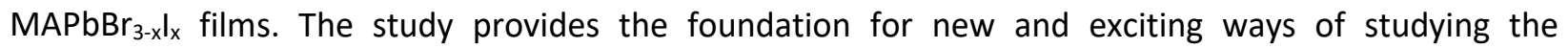
segregation mechanism and thus develop ways to control segregation, thus contributing to the development of high-performance mixed halide perovskites, which can be used for next generation tandem solar cells. 
Acknowledgment: PVK and TE acknowledges the support of the Division of Chemical Sciences, Geosciences, and Biosciences, Office of Basic Energy Sciences of the U.S. Department of Energy, through award DE-FC02-04ER15533. BS would like to thank funding from the Villum Foundation V-SUSTAIN Grant 9455 . TE and BS would also like to acknowledge the support from Technical University of Denmark, with the fellowship for conducting collaborative research at Notre Dame. MK who contributed to the thermodynamic discussion of this work acknowledges the support of the Division of Materials Sciences and Engineering, Office of Basic Energy Sciences, U.S. Department of Energy under Award DE-SC0014334 for financial support. The authors would also like to thank Dr. Tatyana Orlova of the Notre Dame Integrated Imaging Facility for her assistance in obtaining cross-sectional SEM. This is contribution NDRL No. 5261 from the Notre Dame Radiation Laboratory.

Supporting Information: The supporting information contains synthetic and annealing procedures, and experimental procedures (UV-Vis absorbance, SEM, and XPS) and the detailed results on the absorption and XPS measurements. 


\section{References.}

1. Ono, L. K.; Qi, Y.; Liu, S. Progress toward Stable Lead Halide Perovskite Solar Cells, Joule 2018, 2, 1961-1990.

2. Nayak, P. K.; Mahesh, S.; Snaith, H. J.; Cahen, D. Photovoltaic solar cell technologies: analysing the state of the art, Nature Reviews Materials 2019, 4, 269-285.

3. Jena, A. K.; Kulkarni, A.; Miyasaka, T. Halide Perovskite Photovoltaics: Background, Status, and Future Prospects, Chemical Reviews 2019, 119, 3036-3103.

4. Tai, Q.; Tang, K.-C.; Yan, F. Recent progress of inorganic perovskite solar cells, Energy \& Environmental Science 2019, 12, 2375-2405.

5. Zhang, F.; Bi, D.; Pellet, N.; Xiao, C.; Li, Z.; Berry, J. J.; Zakeeruddin, S. M.; Zhu, K.; Grätzel, M. Suppressing defects through the synergistic effect of a Lewis base and a Lewis acid for highly efficient and stable perovskite solar cells, Energy \& Environmental Science 2018, 11, 3480-3490.

6. Saliba, M., et al. Cesium-containing triple cation perovskite solar cells: improved stability, reproducibility and high efficiency, Energy \& Environmental Science 2016, 9, 1989-1997.

7. Dang, H. X., et al. Multi-cation Synergy Suppresses Phase Segregation in Mixed-Halide Perovskites, Joule 2019, 3, 1746-1764.

8. Belisle, R. A.; Bush, K. A.; Bertoluzzi, L.; Gold-Parker, A.; Toney, M. F.; McGehee, M. D. Impact of Surfaces on Photoinduced Halide Segregation in Mixed-Halide Perovskites, ACS Energy Letters 2018, 3, 2694-2700.

9. Luan, J.; Xu, J.; Chen, J.; Shi, X.; Zhang, B.; Dai, S.; Yao, J. Efficient Planar $\mathrm{CH}_{3} \mathrm{NH}_{3} \mathrm{PbBr}_{3}$ Perovskite Solar Cells Prepared at Room Temperature with Ionic-Liquids/Fullerene as an Electron Transport Bilayer, Journal of Solid State Chemistry 2019, 270, 436-442.

10. Schulz, P.; Cahen, D.; Kahn, A. Halide Perovskites: Is It All about the Interfaces?, Chemical Reviews 2019, 119, 3349-3417.

11. Boyd, C. C.; Cheacharoen, R.; Leijtens, T.; McGehee, M. D. Understanding Degradation Mechanisms and Improving Stability of Perovskite Photovoltaics, Chemical Reviews 2019, 119, 34183451.

12. Christians, J. A.; Schulz, P.; Tinkham, J. S.; Schloemer, T. H.; Harvey, S. P.; Tremolet de Villers, B. J.; Sellinger, A.; Berry, J. J.; Luther, J. M. Tailored interfaces of unencapsulated perovskite solar cells for $>1,000$ hour operational stability, Nature Energy 2018, 3, 68-74.

13. Berhe, T. A., et al. Organometal halide perovskite solar cells: degradation and stability, Energy \& Environmental Science 2016, 9, 323-356.

14. Yuan, Y.; Huang, J. Ion Migration in Organometal Trihalide Perovskite and Its Impact on Photovoltaic Efficiency and Stability, Accounts of Chemical Research 2016, 49, 286-293.

15. Samu, G. F.; Janáky, C.; Kamat, P. V. A Victim of Halide Ion Segregation. How Light Soaking Affects Solar Cell Performance of Mixed Halide Lead Perovskites, ACS Energy Letters 2017, 2, 1860-1861.

16. Peng, W.; Aranda, C.; Bakr, O. M.; Garcia-Belmonte, G.; Bisquert, J.; Guerrero, A. Quantification of lonic Diffusion in Lead Halide Perovskite Single Crystals, ACS Energy Letters 2018, 3, 1477-1481.

17. Gualdrón-Reyes, A. F.; Yoon, S. J.; Barea, E. M.; Agouram, S.; Muñoz-Sanjosé, V.; Meléndez, Á. M.; Niño-Gómez, M. E.; Mora-Seró, I. Controlling the Phase Segregation in Mixed Halide Perovskites through Nanocrystal Size, ACS Energy Letters 2019, 4, 54-62.

18. Vashishtha, P.; Halpert, J. E. Field-Driven Ion Migration and Color Instability in Red-Emitting Mixed Halide Perovskite Nanocrystal Light-Emitting Diodes, Chemistry of Materials 2017, 29, 5965-5973.

19. Gualdrón-Reyes, A. F.; Yoon, S. J.; Mora-Seró, I. Recent insights for achieving mixed halide perovskites without halide segregation, Current Opinion in Electrochemistry 2018, 11, 84-90.

20. Shao, Y., et al. Grain boundary dominated ion migration in polycrystalline organic-inorganic halide perovskite films, Energy \& Environmental Science 2016, 9, 1752-1759. 
21. Yang, B., et al. Enhancing Ion Migration in Grain Boundaries of Hybrid Organic-Inorganic Perovskites by Chlorine, Advanced Functional Materials 2017, 27, 1700749.

22. Miyata, K.; Atallah, T. L.; Zhu, X.-Y. Lead halide perovskites: Crystal-liquid duality, phonon glass electron crystals, and large polaron formation, Science Advances 2017, 3, e1701469.

23. Akkerman, Q. A.; D'Innocenzo, V.; Accornero, S.; Scarpellini, A.; Petrozza, A.; Prato, M.; Manna, L. Tuning the Optical Properties of Cesium Lead Halide Perovskite Nanocrystals by Anion Exchange Reactions, Journal of the American Chemical Society 2015, 137, 10276-10281.

24. Ravi, V. K.; Scheidt, R. A.; Nag, A.; Kuno, M.; Kamat, P. V. To Exchange or Not to Exchange. Suppressing Anion Exchange in Cesium Lead Halide Perovskites with $\mathrm{PbSO}_{4}$-Oleate Capping, ACS Energy Letters 2018, 3, 1049-1055.

25. Elmelund, T.; Scheidt, R. A.; Seger, B.; Kamat, P. V. Bidirectional Halide Ion Exchange in Paired Lead Halide Perovskite Films with Thermal Activation, ACS Energy Letters 2019, 4, 1961-1969.

26. Draguta, S.; Sharia, O.; Yoon, S. J.; Brennan, M. C.; Morozov, Y. V.; Manser, J. M.; Kamat, P. V.; Schneider, W. F.; Kuno, M. Rationalizing the Light-Induced Phase Separation of Mixed Halide OrganicInorganic Perovskites, Nature Communications 2018, 8, Article No. 200 (DOI: 10.1038/s41467-01700284-2).

27. Knight, A. J.; Wright, A. D.; Patel, J. B.; McMeekin, D. P.; Snaith, H. J.; Johnston, M. B.; Herz, L. M. Electronic Traps and Phase Segregation in Lead Mixed-Halide Perovskite, ACS Energy Letters 2019, 4, 7584.

28. Futscher, M. H.; Lee, J. M.; McGovern, L.; Muscarella, L. A.; Wang, T. Y.; Haider, M. I.; Fakharuddin, A.; Schmidt-Mende, L.; Ehrler, B. Quantification of Ion Migration in $\mathrm{CH}_{3} \mathrm{NH}_{3} \mathrm{Pbl}_{3}$ Perovskite Solar Cells by Transient Capacitance Measurements, Materials Horizons 2019, 6, 1497-1503.

29. Chatterjee, R.; Pavlovetc, I. M.; Aleshire, K.; Hartland, G. V.; Kuno, M. Subdiffraction Infrared Imaging of Mixed Cation Perovskites: Probing Local Cation Heterogeneities, ACS Energy Letters 2018, 3, 469-475.

30. Tang, X.; van den Berg, M.; Gu, E.; Horneber, A.; Matt, G. J.; Osvet, A.; Meixner, A. J.; Zhang, D.; Brabec, C. J. Local Observation of Phase Segregation in Mixed-Halide Perovskite, Nano Letters 2018, 18, 2172-2178.

31. Brivio, F.; Caetano, C.; Walsh, A. Thermodynamic Origin of Photoinstability in the $\mathrm{CH}_{3} \mathrm{NH}_{3} \mathrm{~Pb}\left(\mathrm{I}_{1-}\right.$ $\left.{ }_{x} \mathrm{Br}_{\mathrm{x}}\right)_{3}$ Hybrid Halide Perovskite Alloy, The Journal of Physical Chemistry Letters 2016, 7, 1083-1087.

32. Bischak, C. G.; Hetherington, C. L.; Wu, H.; Aloni, S.; Ogletree, D. F.; Limmer, D. T.; Ginsberg, N. S. Origin of Reversible Photoinduced Phase Separation in Hybrid Perovskites, Nano Letters 2017, 17, 10281033.

33. Hoke, E. T.; Slotcavage, D. J.; Dohner, E. R.; Bowring, A. R.; Karunadasa, H. I.; McGehee, M. D. Reversible Photoinduced Trap Formation in Mixed-Halide Hybrid Perovskites for Photovoltaics, Chemical Science 2015, 6, 613-617.

34. Yoon, S. J.; Kuno, M.; Kamat, P. V. Shift Happens. How Halide Ion Defects Influence Photoinduced Segregation in Mixed Halide Perovskites, ACS Energy Letters 2017, 2, 1507-1514.

35. Brennan, M. C.; Draguta, S.; Kamat, P. V.; Kuno, M. Light-Induced Anion Phase Segregation in Mixed Halide Perovskites, ACS Energy Letters 2018, 3, 204-213.

36. Unger, E. L.; Kegelmann, L.; Suchan, K.; Sörell, D.; Korte, L.; Albrecht, S. Roadmap and roadblocks for the band gap tunability of metal halide perovskites, Journal of Materials Chemistry A 2017, 5, 1140111409.

37. Balakrishna, R. G.; Kobosko, S. M.; Kamat, P. V. Mixed Halide Perovskite Solar Cells. Consequence of lodide Treatment on Phase Segregation Recovery, ACS Energy Letters 2018, 3, 22672272. 
38. Yoon, S. J.; Draguta, S.; Manser, J. S.; Sharia, O.; Schneider, W. F.; Kuno, M.; Kamat, P. V. Tracking lodide and Bromide Ion Segregation in Mixed Halide Lead Perovskites during Photoirradiation, ACS Energy Letters 2016, 1, 290-296.

39. Bischak, C. G.; Wong, A. B.; Lin, E.; Limmer, D. T.; Yang, P.; Ginsberg, N. S. Tunable Polaron Distortions Control the Extent of Halide Demixing in Lead Halide Perovskites, The Journal of Physical Chemistry Letters 2018, 9, 3998-4005.

40. Azpiroz, J. M.; Mosconi, E.; Bisquert, J.; De Angelis, F. Defect migration in methylammonium lead iodide and its role in perovskite solar cell operation, Energy \& Environmental Science 2015, 8, 21182127.

41. Barker, A. J., et al. Defect-Assisted Photoinduced Halide Segregation in Mixed-Halide Perovskite Thin Films, ACS Energy Letters 2017, 2, 1416-1424.

42. Slotcavage, D. J.; Karunadasa, H. I.; McGehee, M. D. Light-Induced Phase Segregation in HalidePerovskite Absorbers, ACS Energy Letters 2016, 1, 1199-1205.

43. Ruth, A.; Brennan, M. C.; Draguta, S.; Morozov, Y. V.; Zhukovskyi, M.; Janko, B.; Zapol, P.; Kuno, M. Vacancy-Mediated Anion Photosegregation Kinetics in Mixed Halide Hybrid Perovskites: Coupled Kinetic Monte Carlo and Optical Measurements, ACS Energy Letters 2018, 3, 2321-2328.

44. Motti, S. G.; Meggiolaro, D.; Martani, S.; Sorrentino, R.; Barker, A. J.; De Angelis, F.; Petrozza, A. Defect Activity in Metal-Halide Perovskites, Advanced Materials 2019, Art. no.1901183.

45. Motti, S. G., et al. Controlling Competing Photochemical Reactions Stabilizes Perovskite Solar Cells, Nature Photonics 2019, 13, doi: 10.1038/s41566-019-0435-1.

46. Yang, W. S., et al. lodide Management in Formamidinium-Lead-Halide-Based Perovskite Layers for Efficient Solar Cells, Science 2017, 356, 1376-1379.

47. Li, C.; Guerrero, A.; Huettner, S.; Bisquert, J. Unravelling the role of vacancies in lead halide perovskite through electrical switching of photoluminescence, Nature Communications 2018, 9, 5113.

48. Walsh, A.; Stranks, S. D. Taking Control of Ion Transport in Halide Perovskite Solar Cells, ACS Energy Letters 2018, 3, 1983-1990.

49. Wieghold, S., et al. Halide heterogeneity affects local charge carrier dynamics in mixed-ion lead perovskite thin films, Chemistry of Materials 2019, 31, 3712-3721.

50. Samu, G. F.; Balog, Á.; De Angelis, F.; Meggiolaro, D.; Kamat, P. V.; Janáky, C. Electrochemical Hole Injection Selectively Expels lodide from Mixed Halide Perovskite Films, Journal of the American Chemical Society 2019, 141, 10812-10820.

51. Eames, C.; Frost, J. M.; Barnes, P. R. F.; O'Regan, B. C.; Walsh, A.; Islam, M. S. lonic Transport in Hybrid Lead lodide Perovskite Solar Cells, Nat Commun 2015, 6, Article No. 8497 